DOI: 10.12731/2658-6649-2019-11-1-79-89

УДК 615.322:636.2

\title{
ОЦЕНКА ВОЗДЕЙСТВИЯ НА КОМПЛЕКС ХОЗЯЙСТВЕННО-ПОЛЕЗНЫХ КАЧЕСТВ ТЕЛЯТ ЧЕРНО-ПЕСТРОЙ ПОРОДЫ ФАРМСУБСТАНЦИИ НА ОСНОВЕ КРАПИВЫ ДВУДОМНОЙ
}

\author{
Зубова Т.В., Грачев С.Ю., Сапарова Е.И.
}

В статье представлены результаты исследования влияния фармсубстанции крапивы двудомной на рост и развитие телят черно-пестрой nороды.

Цель работы заключалась в установлении оптимальной дозы вводимой фармсубстанции крапивы двудомной для повышения показателей роста и развития телят черно-пестрой породы.

Применение лекарственных растений в ветеринарной практике способствует сокращению падежа молодняка, снижает затрать на дорогостоящиче химиотерапевтические препараты, способствует снижению цены на производство продуктов животноводства. Тем не менее, правильная заготовка и хранение растительного лекарственного сырья требует особых условий, поэтому использование концентрированных вытяжек, до некоторой степени может решить эту проблему. Включение фармсубстанций в состав рациионов с изелью увеличения продуктивности и повышения резистентности организма животных, является основным направлением замены антибиотикотерапии. Это повысит экологическую иенность продукции животноводства.

Материалы и методы. Исследования проводили на телятнике ИП главы Крестьянского (фермерского) хозяйства «Баранов Александр Юрьевич» Юргинского района, Кемеровской области на 6 группах телят, по 6 голов в каждой.

Результаты исследования показали, что введение фармсубстанции крапивы двудомной в дозе 10 мг/кг на голову в сутки способствовало увеличению массы тела телят, приросту живой массы и 100\% сохранности поголовья. 
Заключение. Определен способ и доза введения фармсубстанщии крапивы двудомной, положстельно влияющие на показатели роста и развития телят.

Ключевые слова: крапива двудомная (обыкновенная); фармсубстанция; фитобиотики; сохранность; телята; рост и развитие.

\section{IMPACT ASSESSMENT OF COMPLEX ECONOMIC-USEFUL QUALITIES OF CALVES OF BLACK-MOTLEY BREED OF PHARMACEUTICAL SUBSTANCES ON THE BASIS OF NETTLE}

\section{Zubova T.V., Grachev S.Yu., Saparova E.I.}

The article presents the results of a study of the effect of the pharmaceutical substation nettle dioecious on the growth and development of calves of blackand-white breed.

The aim of the work was to establish the optimal dose of the administered pharmaceutical substation nettle dioecious to increase the growth and development of calves of black-and-white breed. The use of medicinal plants in veterinary practice helps to reduce the mortality of young animals, reduces the cost of expensive chemotherapy drugs, reduces the price of livestock products. However, the correct preparation and storage of herbal medicinal raw materials requires special conditions, so the use of concentrated extracts, to some extent can solve this problem. The inclusion of pharmaceutical substances in the diet in order to increase productivity and increase resistance of animals is the main direction of replacing antibiotic therapy. This will increase the environmental value of livestock products.

Materials and methods. The studies were conducted on the calf farm of the head of the Peasant (farmer) farm "Baranov Alexander Yurievich" of the Yurga district, Kemerovo region on 6 groups of calves, 6 heads each.

The results of the study showed that the introduction of the pharmacy of nettle dioecious at a dose of $10 \mathrm{mg} / \mathrm{kg}$ per head per day contributed to an increase in body weight of calves, an increase in live weight and 100\% safety of livestock.

Conclusion. The method and dose of administration of the pharmaceutical substation nettle dioecious, positively affecting the growth and development of calves.

Keywords: stinging nettle (common); pharmaceutical; phytobiotic; preservation; calves; growth and development. 


\section{Введение}

Опыт проведения исследований в животноводстве и птицеводстве России и других стран, показывает, что использование фитобиотиков в качестве природных кормовых добавок, способствует сокращению приема антибиотиков и оказывает положительное воздействие на повышение продуктивности животных, а также снижает затраты кормов на единицу продукции.

Фитогенные кормовые добавки, чаще всего, не включаются в рационы из-за отсутствия результатов научных испытаний. Это дает основание необходимости в проведения более детальных научно-производственных исследований в области использования фитобиотиков в кормлении сельскохозяйственных животных $[1,2,3]$.

В странах Европейского союза запрет на все виды кормовых антибиотиков действует с 2006 года, поэтому большинство животноводческих предприятий применяет фитобиотики - натуральные кормовые добавки растительного происхождения, оказывающие положительный эффект на пищеварение и общее состояние здоровья животных.

Лекарственные растения используются для профилактики ряда заболеваний животных. Однако, их использование в отдельности и в сборах неудобно в применении в связи с необходимостью приготовления настоев и отваров непосредственно в хозяйстве, где условия, как правило, не соответствуют требованиям ветеринарно-санитарных норм, при этом настои и отвары характеризуются коротким сроком хранения. Также затруднено выпаивание задаваемых лекарственных отваров, настоев в больших объемах из-за специфического запаха и горького вкуса при недостаточной эффективности и больших расходах составляющих компонентов $[3,4,5]$.

На территории Кемеровской области произрастает 52 вида лекарственных растений, допущенных к применению в практике ветеринарной медицины. Резервы сырья установлены для видов, которые по характеру распространения и сырьевой базе могут быть причислены к промысловым, т.е. сырьевая база состоятельна, а также для видов, которые представляют интерес для изготовления фитобиотических препаратов. В фитобиотиках содержится целый комплекс биологически активных веществ, в том числе микро- и макроэлементы, которые положительно влияют на организм животных.

Крапива двудомная (обыкновенная) - Urtica dioica L. Крапивные (Urticaceae) - семейство, включающее в себя около 60 родов и 1000 видов мировой флоры $[6,7]$. 
Распространена почти повсеместно. Растет рядом с жильем, в тенистых местах. В засушливых степных районах и в Средней Азии встречается очень редко. На сегодняшний день проведены исследования вероятности использования в качестве фитобиотиков корней и корневищ [8] для применения в ветеринарной практике, а также в медицине для изготовления перевязочного материала [9].

Листья крапивы содержат аскорбиновую кислоту (до 269 мг\%), витамин К (42-45 мкг/г), витамин В , пантотеновую кислоту [10], каротиноиды (бета-каротин, ксантофилл, виолаксантин) - до 50 мг\%, соли железа [11], кальция и магния [12] и другие вещества. В траве крапивы содержатся важные эссенциальные микроэлементы $(\mathrm{Zn}, \mathrm{Cu}, \mathrm{Mn}, \mathrm{Fe})$ и свинец $(\mathrm{Pb})$ [13]. Препараты крапивы увеличивают свертываемость крови, повышают процентное содержание гемоглобина и количество эритроцитов.

Крапива применяется для лечения телят при заболеваниях желудочно-кишечного тракта $[14,15,16]$, для профилактики и лечения гипо- и авитаминозов, как стимулирующее обмен веществ.

Формирование целей и задач исследования.

Цель работы заключалась в установлении оптимальной дозы вводимой фармсубстанции крапивы двудомной для повышения показателей роста и развития телят черно-пестрой породы.

Для проведения экспериментальных исследований на телятах черно-пестрой породы сформированы контрольная и 5 опытных групп телят в возрасте от 14 дней, по 6 голов в каждой группе. Для проведения индивидуальных взвешиваний применяли электронные весы. Взвешивание проводили в начале и в конце опыта. Телятам контрольной группы скармливали основной рацион, телятам опытных групп - фармсубстанцию на основе экстракта крапивы двудомной согласно схеме опытов.

Изложение основного материала исследований.

Научно-хозяйственный опыт проводили на телятах черно-пестрой породы с 14-дневного возраста, живой массой от 40 до 42 кг. Продолжительность опыта 14 дней. В каждой группе было по шесть голов телят.

Животные всех групп получали одинаковый основной рацион согласно схеме, принятой в хозяйстве. Основной рацион состоял из цельного молока, комбикорма, сена.

Контрольная группа - основной рацион.

I группа-основной рацион и 4,0 мг/кг фармсубстанции крапивы двудомной

II группа-основной рацион и 5,5 мг/кг фармсубстанции крапивы двудомной 
III группа - основной рацион и 7,0 мг/кг фармсубстанции крапивы двудомной

IV группа-основной рацион и 8,5 мг/кг фармсубстанции крапивы двудомной

$\mathrm{V}$ группа - основной рацион и 10 мг/кг фармсубстанции крапивы двудомной на голову в сутки.

В опытах учитывались следующие показатели: физиологическое состояние, живая масса, интенсивность роста и сохранность телят, в зависимости от введения в их рацион различных доз экстракта крапивы.

Фармсубстанцию крапивы двудомной задавали внутрь индивидуально. Содержимое (с определенной дозой для каждого животного) разводили в 5 мл кипяченной и остуженной воды и после растворения выпаивали телятам. Растворы готовили перед применением. Начинали задавать с 14 дня после рождения за 30 минут до кормления или во время очередного кормления по 1 дозе 1 раз в сутки в течение 14 дней.

При ежедневных наблюдениях учитывали основные клинические показатели: общее состояние, аппетит, показатели дыхания, пульса и температуры тела, функции органов пищеварения и мочеотделения, динамику прироста массы тела (табл. 1).

Таблииа 1 .

Клинико-физиологические показатели телят на конец опыта

\begin{tabular}{|l|c|c|c|c|c|c|}
\hline \multirow{2}{*}{\multicolumn{1}{|c|}{ Показатель }} & \multicolumn{6}{|c|}{ Группа (доза экстракта, мг/кг массы тела) } \\
\cline { 2 - 7 } & $\begin{array}{c}\text { кон- } \\
\text { трольная }\end{array}$ & $\begin{array}{c}1 \\
\text { опытная } \\
(4,0)\end{array}$ & $\begin{array}{c}2 \\
\text { опытная } \\
(5,5)\end{array}$ & $\begin{array}{c}3 \\
\text { опытная } \\
(7,0)\end{array}$ & $\begin{array}{c}4 \text { опыт- } \\
\text { ная } \\
(8,5)\end{array}$ & $\begin{array}{c}5 \text { опыт- } \\
\text { ная } \\
(10,0)\end{array}$ \\
\hline Температура тела, ${ }^{0} \mathrm{C}$ & $38,4 \pm 0,01$ & $38,6 \pm 0,02$ & $38,4 \pm 0,01$ & $38,6 \pm 0,02$ & $38,2 \pm 0,01$ & $38,1 \pm 0,03$ \\
\hline $\begin{array}{l}\text { Частота пульса, } \\
\text { ударов/в мин. }\end{array}$ & $80,2 \pm 1,1$ & $81,2 \pm 1,3$ & $78,9 \pm 0,7$ & $79,6 \pm 0,4$ & $81,2 \pm 0,11$ & $78,5 \pm 0,16$ \\
\hline $\begin{array}{l}\text { Частота дыхания, дых. } \\
\text { дв./мин }\end{array}$ & $25,1 \pm 0,5$ & $24,6 \pm 0,4$ & $25,3 \pm 0,5$ & $25,7 \pm 0,3$ & $24,9 \pm 0,3$ & $25,2 \pm 0,4$ \\
\hline $\begin{array}{l}\text { Количество животных с на- } \\
\text { рушением функции ЖКТ }\end{array}$ & 3 & 2 & - & - & - & - \\
\hline
\end{tabular}

Температура тела, частота дыхательных движений в минуту и частота пульса находились в пределах физиологической нормы, отрицательного влияния фармсубстанции не выявлено.

Телята, получавшие фармсубстанцию крапивы двудомной, отличались подвижностью, были энергичны, волосяной покров гладкий, блестящий, аппетит - в пределах нормы. В течение 14 дней в 1 опытной группе, при 
применении фармсубстанции крапивы двудомной в дозе 4 г признаки гастроэнтерита отмечали у 2 телят $(33,2 \%)$ без симптомов нарастания болезни. В контрольной группе гастроэнтеритом заболело 3 теленка (50\%), из них 1 теленок пал.

В опыте все телята, получавшие в качестве кормовой добавки к обычному рациону фармсубстанцию крапивы двудомной, отличались высокой интенсивностью роста и в результате этого имели большую живую массу по сравнению со своими сверстниками из контрольной группы. Разница по этому показателю между контрольной группой и опытными группами составила к концу периода наблюдения от 1,66 до $5,72 \%$ (таблица 2).

Таблица 2.

Интенсивность роста телят при различных дозах введения фармсубстанции

\begin{tabular}{|c|c|c|c|c|c|c|c|}
\hline \multirow[b]{2}{*}{ Показатель } & \multirow[b]{2}{*}{$\begin{array}{l}\text { Ед. } \\
\text { изм. }\end{array}$} & \multicolumn{6}{|c|}{ Группа } \\
\hline & & $\begin{array}{c}\text { контроль- } \\
\text { ная }\end{array}$ & $\begin{array}{c}1-я \\
\text { опыт- } \\
\text { ная }\end{array}$ & $\begin{array}{c}2-я \\
\text { опыт- } \\
\text { ная }\end{array}$ & $\begin{array}{c}\text { 3-я } \\
\text { опыт- } \\
\text { ная }\end{array}$ & $\begin{array}{c}\text { 4-я } \\
\text { опыт- } \\
\text { ная }\end{array}$ & $\begin{array}{c}\text { 5-я } \\
\text { опыт- } \\
\text { ная }\end{array}$ \\
\hline Количество телят & гол. & 6 & 6 & 6 & 6 & 6 & 6 \\
\hline $\begin{array}{l}\text { Живая масса в начале } \\
\text { опыта }\end{array}$ & кг & $41,67 \pm 0,39$ & $\begin{array}{c}41,90 \pm \\
0,26\end{array}$ & $\begin{array}{c}41,33 \pm \\
0,31\end{array}$ & $\begin{array}{c}41,50 \pm \\
0,37\end{array}$ & $\begin{array}{c}41,65 \pm \\
0,44\end{array}$ & $\begin{array}{c}41,47 \pm \\
0,31\end{array}$ \\
\hline $\begin{array}{l}\text { Живая масса в конце } \\
\text { опыта }\end{array}$ & кг & $49,80 \pm 0,38$ & $\begin{array}{c}50,63 \pm \\
0,26 \\
\end{array}$ & $\begin{array}{c}51,05 \pm \\
0,25 \\
\end{array}$ & $\begin{array}{c}51,65 \pm \\
0,67 \\
\end{array}$ & $\begin{array}{c}52,22 \pm \\
0,41 \\
\end{array}$ & $\begin{array}{c}52,65 \pm \\
0,25\end{array}$ \\
\hline Абсолютный прирост & кг & 8,133 & 8,733 & 9,72 & 10,15 & 10,57 & 11,18 \\
\hline Прирост живой массы & Г/сут & 581 & 623 & 694 & 725 & 755 & 799 \\
\hline Сохранность поголовья & $\%$ & 83,3 & 100 & 100 & 100 & 100 & 100 \\
\hline
\end{tabular}

Интенсивность роста телят зависела от дозы, вводимой в рацион фармсубстанции крапивы двудомной.

Выводы исследования и перспективы дальнейших изысканий данного направления. Введение фармсубстанции крапивы двудомной (Urtica dioica), в дозе 10 мг/кг способствовало наибольшему увеличению массы тела телят. Абсолютный прирост массы тела составил 11,18 кг, прирост живой массы - 799,0 г/сутки. Увеличение дозы фармсубстанции крапивы двудомной с 8,5 до 10 мг/кг на голову в сутки не привело к значительным различиям. Разница по массе между телятами 4 и 5 группы не достоверна. Сохранность поголовья во всех опытных группах составила $100 \%$. В контрольной группе $-83,3 \%$.

Таким образом, оптимальной дозой фармсубстанции крапивы двудомной является - 10 мг/кг живой массы телят. 
Статья подготовлена в рамках соглашения с Минобрнауки России от 3.10.2017 года 14.610.21.0016 «Разработка и внедрение новой серии высокоэффективных фитобиотических кормовых добавок на основе экстрактов лекарственных растений для перехода к высокопродуктивному и экологически чистому агрохозяйству». Уникальный идентификатор проекта RFMEF161017X0016.

\section{Список литературы}

1. Куркин В.А. Изучение возможностей комплексной переработки корней и корневищ крапивы двудомной / В.М. Рыжов, Э.А. Балагозян // Известия Самарского научного центра Российской академии наук. 2012. Т. 14. № 1-9. C. 2246-2248.

2. Рыжов В.А. Разработка и промышленное применение отечественных фитобиотиков / В.А. Рыжов, Е.С. Рыжова, В.П. Короткий, А.С. Зенкин, С.С. Марисов // Концепт: научно-методический электронный журнал. 2015. Т. 13. C. 3236-3240.

3. Федосеева Г.М. Дикорастущие и культивируемые лекарственные растения Восточной Сибири / Г.М. Федосеева, В.М. Мирович, Е.Г. Горячкина. Иркутск, 2010. 192 с.

4. Кузина M.O. Крапива и постенница (Urtica L., Parietaria L., Urticaceae) Южного Зауралья в гербарной коллекции Курганского государственного университета / М.О. Кузина, Н.И. Науменко // Зыряновские чтения: материалы Всероссийской научно-практической конференции. 2015. С. 243-244.

5. Лебеда А.Ф. Лекарственные растения / А.Ф. Лебеда, Н. И. Джуренко, А.П. Исайкина // Самая полная энциклопедия. М.: АСТ-Пресс, 2011. 496 с.

6. Куркин В.А. Фитохимическое исследование надземной части одуванчика лекарственного / В.А. Куркин, А.В. Азнагулова // Химия растительного сырья. 2017. № 1. С. 99-105.

7. Прохорова В.А. Крапива двудомная как инновационное сырье для создания изделий медицинского назначения / В.А. Прохорова, О.А. Легонькова, Е.Л. Пехташева // Биотехнология и качество жизни: материалы международной научно-практической конференции. ЗАО «Экспо-биохим-технологии». Москва, 2014. С. 518-519.

8. Тринеева О.В. Определение органических кислот в листьях крапивы двудомной / О.В. Тринеева, А.И. Сливкин, С.С. Воропаева // Вестник Воронежского государственного университета. Серия: Химия. Биология. Фармация. 2013. № 2. С. 215-219.

9. Габайдуллина Р.С. Распределение железа и цинка в почве и тканях крапивы двудомной (Urtica dioica) / Р.С. Габайдуллина, И.С. Юткина, А.З. Каримова, 
О.Н. Немерешина // Научный поиск в современном мире: сборник материалов VIII Международной научно-практической конференции. Махачкала, 2015. C. 23-24.

10. Сорокина А.А. Определение кальция и магния в листьях и настое крапивы двудомной / А.А. Сорокина, Т.А. Скалозубова, А.И. Марахова // Фармация. 2013. № 2. C. 5-8.

11. Юткина И.С. Распределение микроэлементов и аскорбиновой кислоты в почве и тканях крапивы двудомной (Urtica dioica) / И.С. Юткина, Р.С. Евдокимова, А.З. Каримова // Наука и современность. 2014. № 32-1. С. 68-74.

12. Тринеева О.В. Изучение специфического профиля гидроксикоричных кислот листьев крапивы двудомной / О.В. Тринеева, А.И. Сливкин, И.Б. Перова, К.И. Эллер // Лекарственные растения Ботанического сада: научно-практическая конференция, посвящённая 70-летию Ботанического сада ФГБОУ ВО Первого Московского государственного медицинского университета имени И.М. Сеченова / Под ред. И.А. Самылиной, А.Н. Луферова. Москва, 2016. С. 136.

13. Grevsen K., Fretté X.C., Christensen L.P. Concentration and composition of flavonol glycosides and phenolic acids in aerial parts of stinging nettle (Urtica dioica L.) are affected by nitrogen fertilization and by harvest time // Europ. Journ. Hort.Sci. 2008. Vol. 73. № 1, pp. 20-27.

14. Брусенский Н. Использование крапивы двудомной в кормлении кроликов / Н. Брусенский, В.Н. Нефедова // Инновационные технологии в животноводстве: материалы Межвузовской студенческой научно-практической конференции. ФГБОУ ВПО Донской ГАУ. - пос. Персиановский. 2015. С. 142-144.

15. Юткина И.С. Распределение микроэлементов и аскорбиновой кислоты в почве и тканях крапивы двудомной (Urtica dioica) / И.С. Юткина, Р.С. Евдокимова, А.З. Каримова // Наука и современность. 2014. № 32-1. С. 68-74.

16. Лашин А.П. Настои лекарственных растений в профилактике диспепсии у новорожденных телят / А.П. Лашин, Н.В. Симонова, Н.П. Симонова // Вестник Красноярского государственного аграрного университета. 2013. № 5. C. 177-181.

17. Лашин А.П. Фитопрофилактика диспепсии у новорожденных телят / А.П. Лашин, Н.В. Симонова, Н.П. Симонова // Вестник Красноярского государственного аграрного университета. 2015. № 2. С. 189-192.

18. Лашин А.П. Эффективность применения настоев лекарственных растений у новорожденных телят / А.П. Лашин, Н.В. Симонова, Н.П. Симонова // Вестник Красноярского государственного аграрного университета. 2014. № 9. C. $153-157$. 


\section{References}

1. Kurkin V.A., Ryzhov V.M., Balagozyan E.A. Izvestiya Samarskogo nauchnogo tsentra Rossiiskoi akademii nauk. 2012. V. 14. № 1-9, pp. 2246-2248.

2. Ryzhov V.A., Ryzhova E.S., Korotkii V.P., Zenkin A.S., Marisov S.S. Kontsept. 2015. V. 13, pp. 3236-3240.

3. Fedoseeva G.M., Mirovich V.M., Goryachkina E.G. Dikorastushchie i kul'tiviruemye lekarstvennye rasteniya Vostochnoi Sibiri [Wild and cultivated medicinal plants of Eastern Siberia]. Irkutsk, 2010. 192 p.

4. Kuzina M.O., Naumenko N.I. Zyryanovskie chteniya: materialy Vserossiiskoi nauchno-prakticheskoi konferentsii [Zyryanov Readings: Materials of the All-Russian Scientific practical conference]. 2015, pp. 243-244.

5. Lebeda A.F., Dzhurenko N.I., Isaikina A.P. Samaya polnaya entsiklopediya [The most complete encyclopedia]. M.: AST-Press, 2011. 496 p.

6. Kurkin V.A., Aznagulova A.V. Khimiya rastitel'nogo syr'ya. 2017. № 1, pp. 99-105.

7. Prokhorova V.A., Legon'kova O.A., Pekhtasheva E.L. Biotekhnologiya $i$ kachestvo zhizni: materialy mezhdunarodnoi nauchno-prakticheskoi konferentsii [Biotechnology and quality of life: proceedings of an international scientific and practical conference]. ZAO «Ekspo-biokhim-tekhnologii». Moskva, 2014, pp. 518-519.

8. Trineeva O.V., Slivkin A.I., Voropaeva S.S. Vestnik Voronezhskogo gosudarstvennogo universiteta. Seriya: Khimiya. Biologiya. Farmatsiya. 2013. № 2, pp. 215-219.

9. Gabaidullina R.S., Yutkina I.S., Karimova A.Z., Nemereshina O.N. Nauchnyi poisk $v$ sovremennom mire: sbornik materialov VIII Mezhdunarodnoi nauchno-prakticheskoi konferentsii [Scientific Search in modern world: a collection of materials of the VIII International Scientific and Practical Conference]. Makhachkala, 2015, pp. 23-24.

10. Sorokina A.A., Skalozubova T.A., Marakhova A.I. Farmatsiya. 2013. № 2, pp. 5-8.

11. Yutkina I.S., Evdokimova R.S., Karimova A.Z. Nauka i sovremennost'. 2014. № 32-1, pp. 68-74.

12. Trineeva O.V., Slivkin A.I., Perova I.B., Eller K.I. Lekarstvennye rasteniya Botanicheskogo sada: nauchno-prakticheskaya konferentsiya, posvyashchennaya 70-letiyu Botanicheskogo sada FGBOU VO Pervogo Moskovskogo gosudarstvennogo meditsinskogo universiteta imeni I.M. Sechenova [Medicinal plants of the Botanical Garden: scientific-practical conference dedicated to the 70th anniversary of the Botanical Garden FSBEI HE First Moscow State Medical University named after I.M. Sechenov] / Ed. I.A. Samylina, A.N. Luferov. Moskva, 2016. P. 136. 
13. Grevsen K., Fretté X.C., Christensen L.P. Concentration and composition of flavonol glycosides and phenolic acids in aerial parts of stinging nettle (Urtica dioica L.) are affected by nitrogen fertilization and by harvest time. Europ. Journ. Hort.Sci. 2008. Vol. 73. № 1, pp. 20-27.

14. Brusenskii N., Nefedova V.N. Innovatsionnye tekhnologii v zhivotnovodstve: materialy Mezhvuzovskoi studencheskoi nauchno-prakticheskoi konferentsii [Innovative technologies in animal husbandry: materials of the Interuniversity student's scientific-practical conference]. FGBOU VPO Donskoi GAU. - pos. Persianovskii. 2015, pp. 142-144.

15. Yutkina I.S., Evdokimova R.S., Karimova A.Z. Nauka i sovremennost'. 2014. № 32-1, pp. 68-74.

16. Lashin A.P., Simonova N.V., Simonova N.P. Vestnik Krasnoyarskogo gosudarstvennogo agrarnogo universiteta. 2013. № 5, pp. 177-181.

17. Lashin A.P., Simonova N.V., Simonova N.P. Vestnik Krasnoyarskogo gosudarstvennogo agrarnogo universiteta. 2015. № 2, pp. 189-192.

18. Lashin A.P., Simonova N.V., Simonova N.P. Vestnik Krasnoyarskogo gosudarstvennogo agrarnogo universiteta. 2014. № 9, pp. 153-157.

\section{ДАННЫЕ ОБ АВТОРАХ}

Зубова Татьяна Владимировна, профессор кафедры зоотехнии, доктор биологических наук

ФГБОУ ВО «Кемеровский государственный сельскохозяйственный институт»

ул. Марковиева, 5, г. Кемерово, 650056, Российская Федерация suta54@mail.ru

Грачев Сергей Юрьевич, аспирант

ФГБОУ ВО «Кемеровский государственный сельскохозяйственный институт»

ул. Марковиева, 5, г. Кемерово, 650056, Российская Федерация suta54@mail.ru

Сапарова Елена Ивановна, доцент кафедры селекции и генетики в животноводстве, кандидат сельскохозяйственных наук ФГБОУ ВО «Кемеровский государственный сельскохозяйственный институт» ул. Марковиева, 5, г. Кемерово, 650056, Российская Федераиия SaparovaEI@yandex.ru 
DATA ABOUT THE AUTHORS

Zubova Tat'yana Vladimirovna, Professor, Department of Zootechnics, Doctor of Biological Sciences

Kemerovo State Agricultural Institute

5, Markovtsev Str., Kemerovo, 650056, Russian Federation suta54@mail.ru

Grachev Sergei Yur'evich, graduate student

Kemerovo State Agricultural Institute

5, Markovtsev Str., Kemerovo, 650056, Russian Federation suta54@mail.ru

Saparova Elena Ivanovna, Associate Professor of the Department of Breeding and Genetics in Livestock, Candidate of Agricultural Sciences Kemerovo State Agricultural Institute

5, Markovtsev Str., Kemerovo, 650056, Russian Federation SaparovaEI@yandex.ru 